Ferrata Storti Foundation

\title{
Distinguishing essential thrombocythemia JAK2V617F from polycythemia vera: limitations of erythrocyte values
}

\author{
Richard T. Silver ${ }^{1}$ and Spencer Krichevsky ${ }^{1}$ \\ ${ }^{1}$ Richard T. Silver Myeloproliferative Neoplasm Center, Division of Hematology/Medical
} Oncology, Weill Cornell Medicine, New York, NY, USA

Haematologica 2019

Volume 104(11):2200-2205

\section{Correspondence:}

RICHARD T. SILVER

rtsilve@med.cornell.edu

SPENCER KRICHEVSKY

spk2002@med.cornell.edu

Received: December 11, 2018.

Accepted: April 3, 2019.

Pre-published: April 42019.

doi:10.3324/haematol.2018.213108

Check the online version for the most updated information on this article, online supplements, and information on authorship \& disclosures: www.haematologica.org/content/104/11/2200

(C)2019 Ferrata Storti Foundation

Material published in Haematologica is covered by copyright. All rights are reserved to the Ferrata Storti Foundation. Use of published material is allowed under the following terms and conditions:

https://creativecommons.org/licenses/by-nc/4.0/legalcode. Copies of published material are allowed for personal or internal use. Sharing published material for non-commercial purposes is subject to the following conditions:

https://creativecommons.org/licenses/by-nc/4.0/legalcode, sect. 3. Reproducing and sharing published material for commercial purposes is not allowed without permission in writing from the publisher.

\section{ABSTRACT}

$\mathrm{D}$ istinguishing essential thrombocythemia JAK2V617F from polycythemia vera is difficult because of shared mutation and phenotypic characteristics. The World Health Organization suggested hemoglobin and hematocrit values to diagnose polycythemia vera (PV), but their sensitivity and specificity were not tested. Moreover, red cell values do not accurately predict red cell mass, which we use to discriminate essential thrombocythemia JAK2V617F from PV. Eighty-three PV and 39 essential thrombocythemia JAK2V617F patients were diagnosed based on JAK2V617F positivity, chromium-51 red cell mass, and marrow biopsy findings. Red cell values used to construct a receiver operating characteristic analysis determined optimal thresholds for distinguishing essential thrombocythemia JAK2V617F from PV. Red cell value frequencies were plotted determining if overlap existed. Chromium-51 red cell mass separated PV from essential thrombocythemia JAK2V617F, but red cell values overlapped in $25.0-54.7 \%$. Our data indicate that a significant proportion of PV patients may be underdiagnosed by using only red cell values. A bone marrow biopsy was performed in 199 of $410(48.5 \%)$ and a serum erythropoietin value was measured in 225 of $410(54.9 \%)$ of potential PV patients at our institution. Without isotope studies, marrow biopsies and serum erythropoietin values should improve diagnostic accuracy and become mandatory, but clinical data suggest these tests have not been routinely performed. Therefore, the clinical hematologist must be aware of imperfect accuracy when using only red cell values for distinguishing essential thrombocythemia JAK2V617F from PV.

\section{Introduction}

The JAK2V617F and exon 12 mutations are critical for the diagnosis of polycythemia vera (PV); JAK2V617F is also the molecular marker of $50-60 \%$ of patients with essential thrombocythemia $\left(\mathrm{ET}^{J A K 2 V 617 \mathrm{~F}}\right) .{ }^{1}$ Distinguishing these illnesses in their early stages remains a clinical problem because of their shared mutation and phenotypic characteristics. ${ }^{2,3}$

In clinical situations when the hematocrit (HCT), hemoglobin (HGB), or red blood cell $(\mathrm{RBC})$ count are relatively increased, we distinguish $\mathrm{ET}^{J A K 2 V 617 \mathrm{~F}}$ from PV using chromium-51 (Cr-51) labeled RBC and iodine-135 (I135) to measure red cell mass (RCM) and plasma volume, respectively. ${ }^{4} \mathrm{We}$ include the latter to determine if an elevated HCT is attributed to reduced plasma volume when the Cr-51 determined RCM is normal. The distinction of these diagnoses has clinical significance: if a presumptive $\mathrm{ET}^{\mid J K 2 V 617 \mathrm{~F}}$ patient in fact has $\mathrm{PV}$, a significant risk for thrombosis may incur because therapeutic phlebotomy is not performed. Conversely, if a patient is misdiagnosed with $\mathrm{PV}$, inappropriate phlebotomy treatment may cause significant iron deficiency and other related complications. ${ }^{5}$ In addition, a misdiagnosis may also affect prognostic models comparing $\mathrm{ET}^{J A K 2 V 617 F}$ with PV, $\mathrm{ET}^{\text {CALR, }}$, or $\mathrm{ET}^{M P L}$.

The majority of hematology centers worldwide do not use isotope techniques but instead rely on arbitrarily defined World Health Organization (WHO) 2016 
Table 1. Demographic and hematologic data of polycythemia vera $(\mathrm{PV})$ and essential thrombocythemia $\left(\mathrm{ET}^{\text {TAk2V617F }}\right)$ patients at diagnosis.

\begin{tabular}{|c|c|c|c|c|}
\hline & PV P & $(n=83)$ & ET F & $(n=39)$ \\
\hline & Men $(n=45)$ & Women $(n=38)$ & $\operatorname{Men}(n=12)$ & Women $(n=27)$ \\
\hline Age median, range (yrs) & $53.0(28.0-80.0)$ & $57.0(27.0-78.0)$ & $53.5(29.0-77.0)$ & $51.0(24.0-76.0)$ \\
\hline HCT mean \pm SD (\%) & $50.9 \pm 4.4$ & $51.2 \pm 5.8$ & $43.5 \pm 4.4$ & $42.8 \pm 2.2$ \\
\hline HGB mean $\pm \mathrm{SD}(\mathrm{g} / \mathrm{dL})$ & $17.1 \pm 1.7$ & $16.7 \pm 1.8$ & $14.9 \pm 1.6$ & $14.4 \pm 0.8$ \\
\hline $\mathrm{RBC}$ mean $\pm \mathrm{SD}\left(\mathrm{x} 10^{12} / \mathrm{L}\right)$ & $5.8 \pm 0.6$ & $6.0 \pm 0.9$ & $4.9 \pm 0.8$ & $4.8 \pm 0.4$ \\
\hline RCM mean \pm SD (\%) & $141.7 \pm 14.4$ & $149.4 \pm 24.5$ & $91.8 \pm 15.9$ & $96.1 \pm 14.8$ \\
\hline Plasma volume mean \pm SD (\%) & $(\mathrm{n}=28) 105.1 \pm 15.0$ & $(\mathrm{n}=21) 99.4 \pm 15.3$ & $91.2 \pm 9.4$ & $(\mathrm{n}=26) 99.1 \pm 11.5$ \\
\hline SEV mean \pm SD $(\mathrm{mU} / \mathrm{mL})$ & $(n=41) 4.2 \pm 2.9$ & $(n=35) 2.8 \pm 1.6$ & $(n=9) 5.8 \pm 2.1$ & $(n=14) 5.6 \pm 3.0$ \\
\hline
\end{tabular}

n: number; yrs: years; HCT: hematocrit; HGB: hemoglobin; RBC: red blood cell count; RCM: red cell mass; SD: standard deviation; SEV: serum erythropoietin values.

HCT and HGB threshold values ${ }^{6}$ as surrogates for RCM to help diagnose and distinguish these diseases. ${ }^{7}$ These unconfirmed values were derived from a retrospective study and do not discriminate all cases of $\mathrm{ET}^{\mathrm{JAK} 2 \mathrm{~V} 6 \mathrm{~T} 7 \mathrm{~F}}$ from $\mathrm{PV}^{2,7}$ For this reason, the WHO has advocated marrow biopsy and serum erythropoietin values (SEV), although it is not clear how frequently these tests are actually performed in clinical practices.

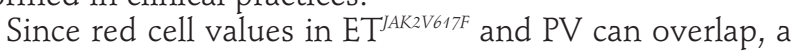
proportion of both diseases may be misdiagnosed. Therefore, we decided to systematically study the sensitivity and specificity of distinguishing $\mathrm{ET}^{J A K 2 V G 17 F}$ with relatively high-normal red blood values from $\mathrm{PV}$ in patients when the RCM had been confirmed by isotope studies. Using a newly devised database-querying tool, we also determined the frequency of marrow biopsy and SEV testing, both of which we use at our own intuition.

\section{Methods}

The Institutional Review Board of Weill Cornell Medicine (WCM) approved this study. Signed informed consent was obtained in accordance with the Declaration of Helsinki.

The diagnosis of PV in our patients was established according to our previously published criteria which included JAK2V617F positivity, a Cr-51 isotope measured $\mathrm{RCM} \geq 125 \%$ of expected volume, and a marrow biopsy consistent with PV., The diagnosis of $\mathrm{ET}^{\text {JAK2V617F }}$ in our patients was established using JAK2V617F positivity, a Cr-51 isotope measured $\mathrm{RCM}<125 \%$ of expected volume, WHO 2007 criteria, ${ }^{1}$ and a marrow biopsy consistent with $\mathrm{ET}^{8} \mathrm{ET}^{J A K 2 V 617 F}$ patients presenting with "high-normal" blood values (women: HCT $>42.0 \%$, HGB $>14.0$ g/dL; men: HCT $>45.0 \%$, HGB $>15.0 \mathrm{~g} / \mathrm{dL}$ ) prompted an RCM study and were selected for this review.

We used a bioinformatics tool developed at WCM to search our electronic medical records for patients with an International Classification of Diseases (ICD) 9 or 10 code for PV or ET who had an RCM study performed from 2004-2017. ${ }^{9}$

Utilizing a receiver operating characteristic (ROC) analysis, we then determined threshold values for HCT, HGB, and RBC to establish limits of specificity and sensitivity. The ROC analysis calculates the optimal combination of sensitivity and specificity thresholds within a range of values to determine which one is the most accurate for diagnosis. We then plotted these ROC-derived threshold values and the frequencies of red cell values obtained at the time of isotope studies to ascertain whether there was any overlap between $\mathrm{ET}^{J A K 2 \mathrm{~V} 617 \mathrm{~F}}$ and PV.

\section{Results}

Of 157 patients who had an RCM study performed, 35 were excluded because of JAK2V617F and exon 12 negativity; of the remaining 122 patients, 83 PV and $39 \mathrm{ET}^{\text {JAK2V617F }}$ patients met study requirements. Relevant demographic and hematologic data of these patients, including age, HCT, HGB, RBC, RCM, and plasma volume are shown in Table 1 . The blood values were recorded at the time of isotope study and prior to any treatment, including phlebotomy. The median age for male and female PV patients was $53.0(28.0-80.0)$ and $57.0(27.0-78.0)$ years, respectively. The median age for male and female $\mathrm{ET}^{\mathrm{JAK} 2 \mathrm{~V} 617 \mathrm{~F}}$ patients was 53.5 (29.0-77.0) and 51.0 (24.0-76.0) years, respectively. For male PV patients, the mean HCT was $50.9 \pm 4.4 \%$, the mean $\mathrm{HGB} 17.1 \pm 1.7 \mathrm{~g} / \mathrm{dL}$, and the mean $\mathrm{RBC}$ count $5.8 \pm 0.6 \times 10^{12} / \mathrm{L}$. For female PV patients, the mean HCT was $51.2 \pm 5.8 \%$, the mean $\mathrm{HGB} 16.7 \pm 1.8 \mathrm{~g} / \mathrm{dL}$, and the mean RBC count $6.0 \pm 0.9 \times 10^{12} / \mathrm{L}$. For male $\mathrm{ET}^{J A K 2 V 617 F}$ patients, the mean HCT was $43.5 \pm 4.4 \%$, the mean HGB $15.4 \pm 1.6 \mathrm{~g} / \mathrm{dL}$, and the mean $\mathrm{RBC}$ count $4.9 \pm 0.8 \times 10^{12} / \mathrm{L}$. For female ET $\mathrm{ET}^{J A K 617 F}$ patients, the mean HCT was $42.8 \pm 2.2 \%$, the mean HGB $14.4 \pm 0.8 \mathrm{~g} / \mathrm{dL}$, and the mean RBC count $4.8 \pm 0.4 \times 10^{12} / \mathrm{L}$. The mean $\mathrm{Cr}-51 \mathrm{RCM}$ of all 83 PV patients was $145.3 \pm 20.1 \%$, greater than $125 \%$ above the expected value and thus establishing polycythemia; ${ }^{4}$ it was measured in 39 presumptive ET ${ }^{J A K 2 V 617 F}$ and it was nor$\mathrm{mal}$ in all of them (mean: $94.8 \pm 15.3 \%$ ). These RCM values show a clear distinction because unlike in red cell values, there was no overlap in values. The mean plasma volume was measured in 49 of 83 PV patients and it was $102.7 \pm 15.4 \%$. The mean plasma volume was measured in 38 of $39 \mathrm{ET}^{\mathrm{JAK} 2 \mathrm{~V} 617 \mathrm{~F}}$ patients and was $96.6 \pm 11.5 \%$. The difference in plasma volume for all patients with PV and $\mathrm{ET}^{J A K 2 V 617 F}$ was statistically significant $(P=0.04)$ due to differences for male patients $(P=0.01)$, but not for female patients $(P=0.94)$. In addition, there was a weak correlation between HCT and plasma volume $(r=-0.05)$. The mean serum erythropoietin value (SEV) was measured in 76 of $83 \mathrm{PV}$ patients and was $3.5 \pm 2.5 \mathrm{mU} / \mathrm{mL}$. The mean SEV was measured in 23 of $40 \mathrm{ET}^{\text {JAK2V617F }}$ patients and was $5.7 \pm 2.7 \mathrm{mU} / \mathrm{mL}$.

Receiver operating characteristic (ROC) analyses were performed to determine optimal threshold values of HCT, $\mathrm{HGB}$, and RBC to discriminate $\mathrm{ET}^{\mathrm{JAK} 2 \mathrm{~V} 617 \mathrm{~F}}$ from PV. The threshold values for distinguishing $\mathrm{ET}^{\text {JAK2V617F }}$ from PV in men and women, respectively, are HCT: 49.3 and $47.9 \%$, HGB: 16.8 and $15.3 \mathrm{~g} / \mathrm{dL}$, and RBC: 5.8 and $5.1 \times 10^{12} / \mathrm{L}$ 
(Table 2). Figure 1A shows ROC curves for HCT in men and women with $\mathrm{ET}^{\mathrm{JAK} 2 \mathrm{~V} 617 \mathrm{~F}}$ and PV; Figure $1 \mathrm{~B}$ shows this for HGB concentration and Figure $1 \mathrm{C}$ shows this for RBC counts. The computer-calculated area under the curve (AUC) measures how well ET ${ }^{J A K 2 V 617 F}$ and PV patients are distinguished using HCT, HGB, or RBC. AUC ranges from 0 to 1 , inclusive, with 1 representing a perfectly specific and sensitive test. For men, the AUC for HCT is 0.819 ( specificity $=100.0 \%$, sensitivity $=64.4 \%$ ) indicating that by using this sole criterion, $100.0 \%$ of male ET JAK2V617F patients, but only $64.4 \%$ of male PV patients, would be correctly diagnosed. For men, the AUC for HGB is 0.753
( specificity $=100.0 \%$, sensitivity $=62.8 \%$ ) indicating that $100.0 \%$ of male $\mathrm{ET}^{\mathrm{J}{ }^{A K}{ }^{2 V 617 F}}$ patients, but only $62.8 \%$ of male PV patients, would be correctly diagnosed. For men, the AUC for RBC is 0.761 (specificity $=100.0 \%$, sensitivity $=52.5 \%$ ) indicating that $100.0 \%$ of male $\mathrm{ET}^{\text {JAK2V617F }}$ and $52.5 \%$ of male PV patients would be correctly diagnosed. For women, the AUC for HCT is 0.957 (specificity $=100.0 \%$, sensitivity $=71.1 \%$ ), for HGB 0.875 (specificity $=88.9 \%$, sensitivity $=75.0 \%$ ), and for RBC 0.924 (specificity $=81.5 \%$, sensitivity $=87.1 \%$ ). The implications of these varying specificities and sensitivities are as previously noted above for men.
A
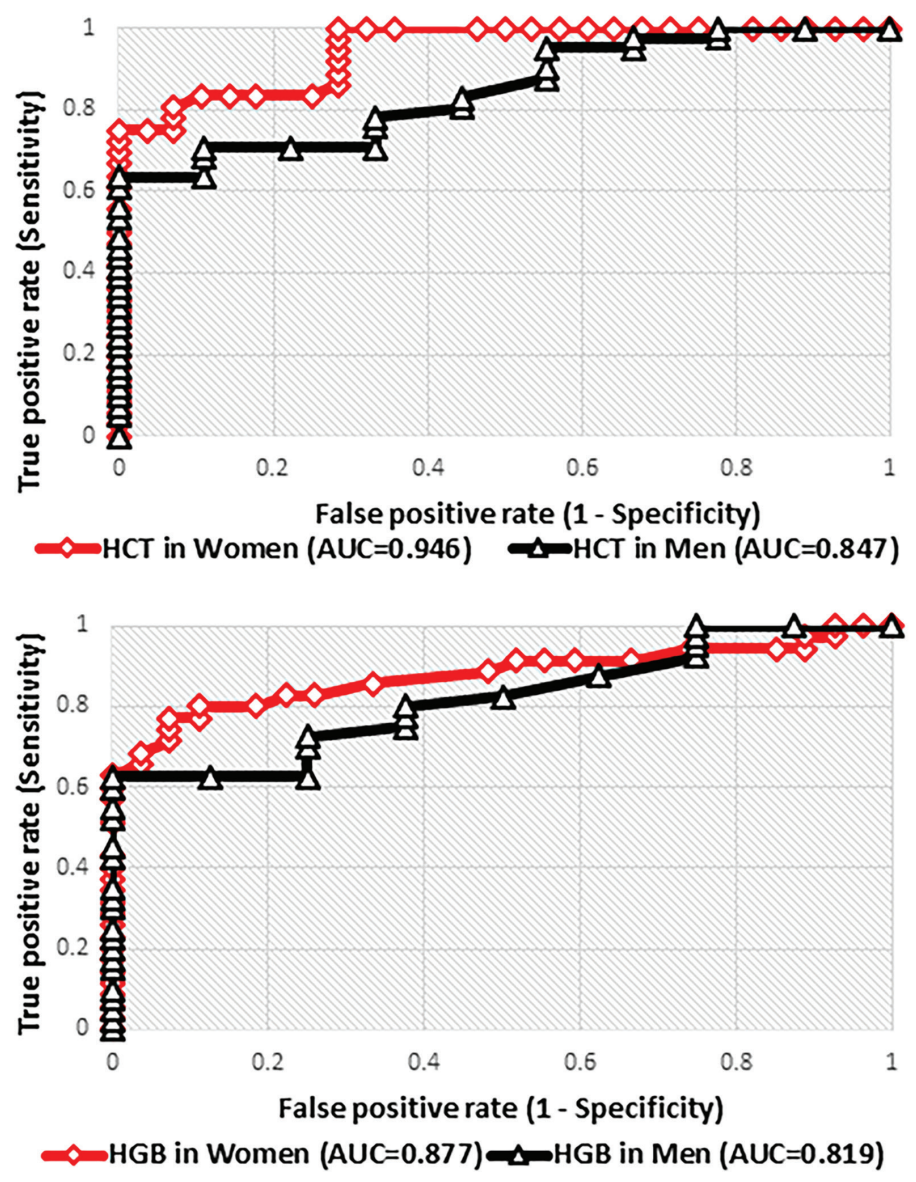

C

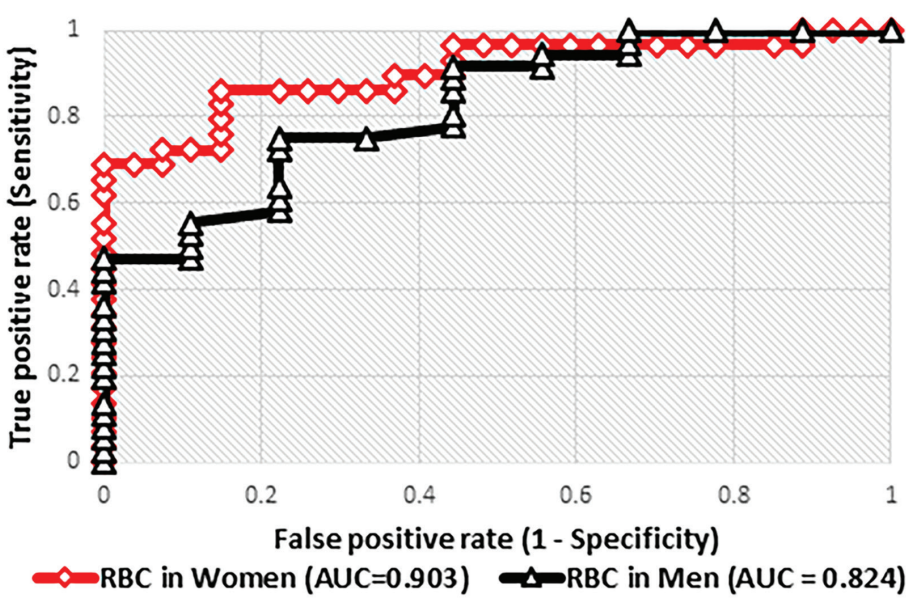

Figure 1. Receiver operating characteristic (ROC) analysis curves of red cell values in men with polycythemia vera $(\mathrm{PV})$ versus men with essential thrombocythemia $\left(\mathrm{ET}^{\text {गAK2V617F }}\right.$ ) (triangle markers) and women with $\mathrm{PV}$ versus women with $\mathrm{ET}^{\mathrm{JAK} 2 \mathrm{~V} 617 \mathrm{~F}}$ (diamond markers). (A) For hematocrit (HCT), (B) for hemoglobin (HGB), and (C) for red blood cells (RBC). 
For patients with either $\mathrm{ET}^{\mathrm{JAK} 2 \mathrm{~V} 617 \mathrm{~F}}$ or PV, the HCT values overlap in $36.0 \%$ of men and $25.0 \%$ of women (Figure $2 \mathrm{~A}$ ), the HGB values overlap in $40.0 \%$ of men and $54.7 \%$ of women (Figure 2B), and the RBC values overlap in $44.0 \%$ of men and $35.9 \%$ of women (data not shown). In these figures, the threshold values are shown in vertical, solid lines.

Querying our outpatient and inpatient electronic medical records with a bioinformatics tool provisioned by WCM showed that of 410 presumptive PV patients, 199 $(48.5 \%)$ and $225(54.9 \%)$ had a marrow biopsy performed and a SEV measured, respectively.

\section{Discussion}

For more than half a century, it has been emphasized that a single HCT or HGB determination cannot be used as a surrogate for RCM.,10,11 Additional errors in blood count values are compounded by poor techniques of obtaining blood samples and other issues affecting plasma volume. We attempt to minimize these errors by collecting blood samples at the same time of the day insofar as possible and by using a standardized blood collection technique. ${ }^{12}$ To attain an accurate RCM and plasma volume, we employ a dual isotope technique, using Cr-51 and I135 to measure these values simultaneously. In this study, as expected, the plasma volume was increased in $\mathrm{PV}^{4,10}$ We have no explanation for the gender differences, but insights may be learned from a larger sample size. The normal RCM and reduced plasma volume found in $\mathrm{ET}^{\text {JAK2V6 } 77 \mathrm{~F}}$ patients accounted for the increased red cell values at the time of diagnosis.
An insufficient number of matched Cr-51 RCM and marrow results from our patients precluded comparison or correlation, which we plan to carry out as a future study. Discriminating $\mathrm{ET}^{\mathrm{JAK} 2 \mathrm{~V} 617 \mathrm{~F} F}$ from $\mathrm{PV}$ is hierarchal with a dual isotope RCM study remaining the "gold standard". We recognize that many institutions cannot perform the standard dual isotope technique, ${ }^{13}$ in this situation, we espouse the use of marrow biopsy, which is now performed in all potential MPN patients at our institution at diagnosis, even in patients with a measured Cr-51 RCM to evaluate baseline fibrosis and cellularity to assess subsequent response to treatment. ${ }^{14}$ It would be of interest to correlate marrow biopsy and Cr-51 RCM findings in the future. Despite the usefulness of a diagnostic marrow findings, as reported by us and others, ${ }^{4,8}$ such findings have not been universally accepted $d^{15-17}$ and even the value of marrow examination in general has been questioned. ${ }^{18}$

Although the SEV is a WHO 2016 minor criterion for the diagnosis of $\mathrm{PV}^{6}$, we emphasize that approximately $15 \%$ of PV patients have a normal SEV $(4-27 \mathrm{mU} / \mathrm{mL}))^{19,20}$ This fact and the availability of isotope studies may account for the relatively infrequent use of this test at our institution in the past. However, this laboratory value may be used in combination with abnormal red cell values to distinguish $\mathrm{ET}^{\mathrm{JAK} 2 \mathrm{~V} 617 \mathrm{~F}}$ from $\mathrm{PV}$ with higher accuracy than using red cell values exclusively.

There are no published data regarding the frequency with which marrow biopsy and SEV are currently performed in patients with PV at diagnosis by general hematologists. We reviewed marrow performance at our institution over the past decade and found that marrow biopsies were performed in 199 of 410 (48.5\%) and an SEV
A
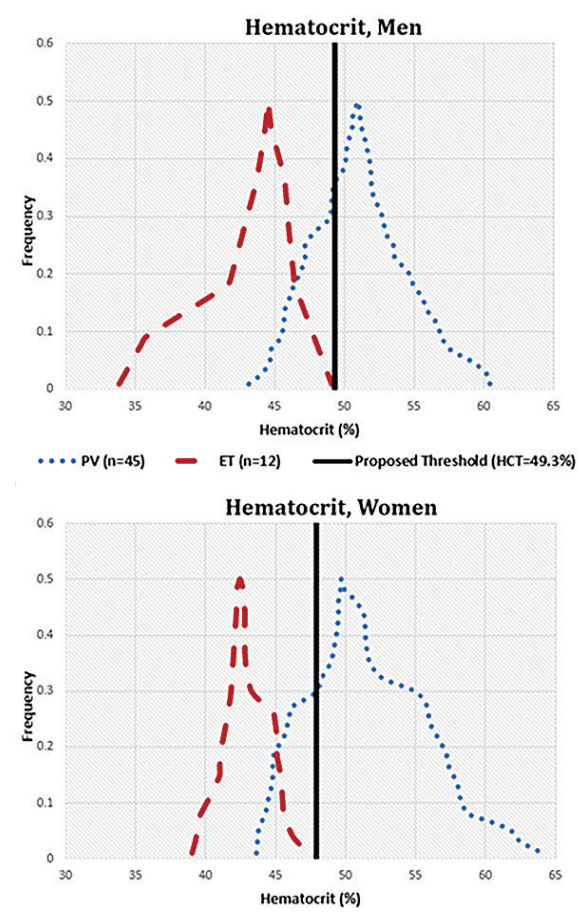

B
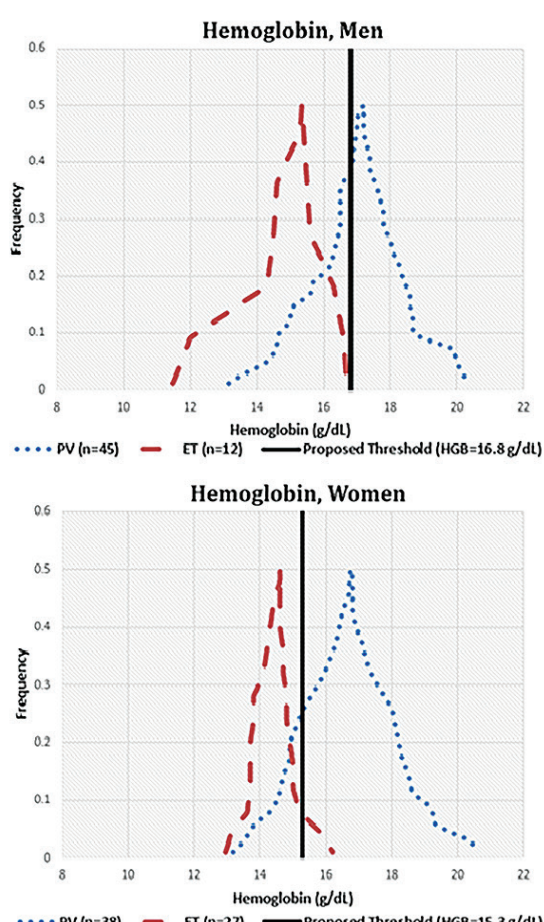

C
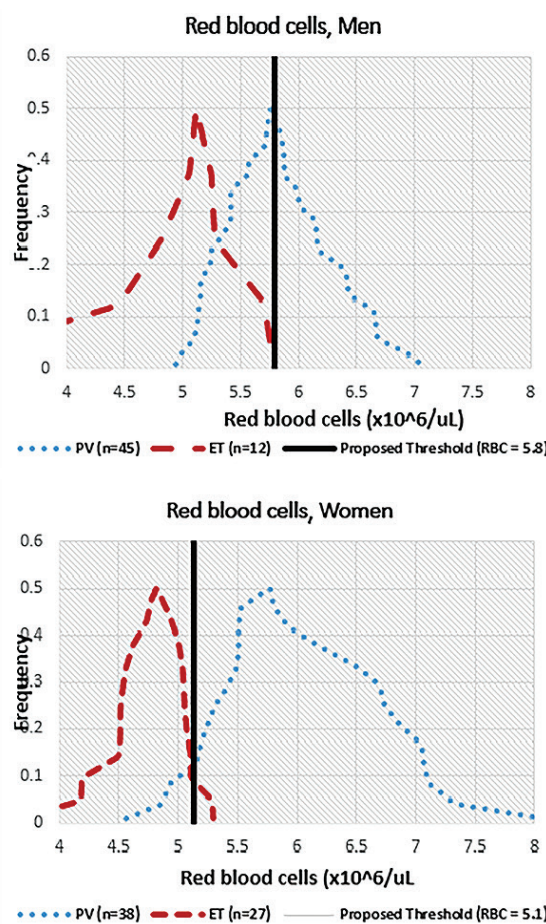

Figure 2. Frequencies of red cell values in men and women with polycythemia vera (PV) (dotted curve) and essential thrombocythemia (ET $\mathrm{T}^{\text {JA2 } 2617 F}$ ( (dashed curve). Proposed thresholds shown in black, vertical line. (A) For hematocrit (HCT), (B) for hemoglobin (HGB), and (C) for red blood cells (RBC). 
Table 2. Threshold values of hematocrit (HCT), hemoglobin (HGB), or red blood cell (RBC) count for men and women with associated area under the curve (AUC), specificity, and sensitivity.

\begin{tabular}{|c|c|c|c|c|c|}
\hline & Value & Threshold & AUC & Specificity (\%) & Sensitivity (\%) \\
\hline \multirow{3}{*}{ Men } & HCT (\%) & 49.3 & 0.819 & 100.0 & 64.4 \\
\hline & HGB (g/dL) & 16.8 & 0.753 & 100.0 & 62.8 \\
\hline & $\mathrm{RBC}\left(\times 10^{12} / \mathrm{L}\right)$ & 5.3 & 0.761 & 100.0 & 52.5 \\
\hline \multirow{3}{*}{ Women } & HCT (\%) & 47.9 & 0.957 & 100.0 & 71.1 \\
\hline & HGB $(\mathrm{g} / \mathrm{dL})$ & 15.3 & 0.875 & 88.9 & 75.0 \\
\hline & $\mathrm{RBC}\left(\mathrm{x} 10^{12} / \mathrm{L}\right)$ & 5.1 & 0.924 & 81.5 & 87.1 \\
\hline
\end{tabular}

was measured in 225 of 410 (54.9\%) PV patients. Of those that did not have a marrow biopsy, the majority had been encountered for only a single visit so that a marrow biopsy was not temporally feasible or the patient was advised to have it performed with their primary hematologist.

In the absence of isotope studies and an initial marrow biopsy or SEV, it is important to evaluate the accuracy, as defined statistically, of the HCT, HGB, and RBC threshold values that are advocated to distinguish $\mathrm{ET}^{\mathrm{JAK} 2 \mathrm{V6} 17 \mathrm{~F}}$ from PV. We found overlap in HCT, HGB, and RBC values ranging from $25.0-54.7 \%$ indicating that a single red cell value will not effectively distinguish $\mathrm{ET}^{\mathrm{JAK} 2 \mathrm{~V} 617 \mathrm{~F}}$ from PV.

Such considerations have been overlooked in other studies. For example, it has been suggested that ET ${ }^{\text {JAK2V617F }}$ patients are at higher risk for thrombosis than those with a CALR mutation. ${ }^{21}$ However, those patients diagnosed with $\mathrm{ET}^{\mathrm{JAK} 2 \mathrm{~V} 617 \mathrm{~F}}$ had a median SEV of $4.7 \mathrm{mU} / \mathrm{mL}$ (range: 0 $47 \mathrm{mU} / \mathrm{mL}$ ) compared with CALR+ ET patients who had a median SEV of $9.4 \mathrm{mU} / \mathrm{mL}$ (range: $1.2-27 \mathrm{mU} / \mathrm{mL}$ ). An unspecified number of $\mathrm{ET}^{\mathrm{JAK} 2 \mathrm{~V} 617 \mathrm{~F}}$ patients had a SEV below normal (i.e. $<4 \mathrm{mU} / \mathrm{mL})^{22}$ suggesting the possibility of PV. Since neither all red cell values, isotope studies, nor systematic marrow biopsies were reported, some of these $\mathrm{ET}^{J A K 2 V 617 \mathrm{~F}}$ patients might have, in fact, had a higher risk of thrombotic events because they actually had PV. ${ }^{23}$ Thus, they were incorrectly assigned to a disease with a decreased expected survival. ${ }^{24}$ Of course, these issues do not occur in JAK2V617F wild-type, CALR ${ }^{+}$, or $\mathrm{MPL}^{+}$ patients because these mutations, with very rare exceptions, do not occur in PV. ${ }^{18}$

It is of interest that our threshold values are coincidentally similar to the WHO 2016 criteria, ${ }^{6}$ which did not address the important topic of imperfect specificity and sensitivity. Although marrow biopsy and SEV are advantageous for distinguishing $\mathrm{ET}^{\text {JAK2V617F }}$ from PV, it is unclear how frequently these examinations are being performed in actual clinical practice. Our data support their use even despite the discussed limitations. In the absence of resolving these discrepancies, isotope RCM studies remain the gold standard for discriminating $\mathrm{ET}^{\text {JAK2V617F }}$ from PV.

In summary, the clinical hematologist must be warned of the varying specificity and sensitivity and the considerable limitations of discriminating $\mathrm{ET}^{\mathrm{JAK} 2 \mathrm{~V} 617 \mathrm{~F}}$ from PV solely when using red cell values, and the importance of isotope, marrow, and SEV studies as outlined by WHO 2016 criteria. ${ }^{6}$ It remains undetermined how frequently any of these tests are performed in clinical practice.

\section{Acknowledgments}

We thank Dr. Paul Christos for statistical review. He was partially supported by the Clinical and Translational Science Center, Weill Cornell Medical College (UL1-TR000457-06).

\section{Funding}

This study was supported in part by the William and Judy Higgins Trust and the Johns Family Foundation of the Cancer Research and Treatment Fund Inc., New York, NY, USA.

\section{References}

1. Tefferi A, Thiele J, Orazi A, et al. Proposals and rationale for revision of the World Health Organization diagnostic criteria for polycythemia vera, essential thrombocythemia, and primary myelofibrosis: recommendations from an ad hoc international expert panel. Blood. 2007;110(4):1092-1097.

2. Barbui T, Thiele J, Kvasnicka HM, Carobbio A, Vannucchi AM, Tefferi A. Essential thrombocythemia with high hemoglobin levels according to the revised WHO classification. Leukemia. 2014: 28(10):2092-2094

3. Spivak JL. Myeloproliferative Neoplasms. N Engl J Med. 2017;377(9):895-896.

4. Silver RT, Chow W, Orazi A, Arles SP, Goldsmith SJ. Evaluation of WHO Criteria for Diagnosis of Polycythemia Vera: A
Prospective Analysis. Blood. 2013; 22(11):1881-1886.

5. Silver RT, Kiladiian JJ, Hasselbalch HC. Interferon and the treatment of polycythemia vera, essential thrombocythemia and myelofibrosis. Exp Rev Hematol. 2013;6(1):49-58.

6. Arber DA, Orazi A, Hasserjian R, et al. The 2016 revision to the World Health Organization (WHO) classification of myeloid neoplasms and acute leukemia. Blood. 2016;127(20):2391-2405.

7. Barbui $\mathrm{T}$, Thiele J, Gisslinger $\mathrm{H}$, et al. Masked polycythemia vera (mPV): Results of an international study. Am J Hematol. 2014;89(1):52-54

8. Kvasnicka HM, Orazi A, Thiele J, Barosi G, Bueso-Ramos CE, Vannucchi AM. European LeukemiaNet study on the reproducibility of bone marrow features in masked polycythemia vera and differentia- tion from essential thrombocythemia. Am J Hematol. 2017;92(1):1062-1067.

9. Overhage JM, Ryan PB, Reich CG, Hartzema AG, Stang PE. Validation of a common data model for active safety surveillance research. J Am Med Inform Assoc. 2012;19(1):54-60

10. Alvarez-Larran A, Ancochea A, Angona A, et al. Red cell mass measurement in patients with clinically suspected diagnosis of polycythemia vera or essential thrombocythemia. Haematologica. 2012; 97(11): 1704-1707

11. Johansson PL, Safai-Kutti S, Kutti J. An elevated haemoglobin concentration cannot be used as a surrogate marker for absolute erythrocytosis: a study of patients with polcythaemia vera and appartent polycythaemia. Br J Haematol. 2005;129(5):701705.

12. Silver RT, Gjoni S. The hematocrit value in 
polycythemia vera: caveat utilitor. Leuk Lymphoma. 2015;56(6):1540-1541.

13. Margolskee E, Orazi A, Krichevsky S, Silver RT. Evaluation of bone marrow morphology is essential for assessing disease status in interferon-treated polycythemia vera patients. Haematologica. 2017;102(3):e97e99.

14. Alvarez-Larran A, Ancochea A, Garcia M, et al. WHO-histological criteria for myeloproliferative neoplasms: reproducibility, diagnostic accuracy and correlation with gene mutations and clinical outcomes. Br J Haematol. 2014;166(6):911-919.

15. Ellis JT, Silver RT, Coleman M, Geller SA. The bone marrow in polycythemia vera. Semin Hematol. 1975;12(4):433-444.

16. Wilkins BS, Erber WN, Bareford D, et al. Bone marrow pathology in essential thrombocythemia: interobserver reliability and utility for identifying disease subtypes.
Blood. 2008:111(1):60-70.

17. Spivak J. Polycythemia Vera. Curr Treat Options Oncol. 2018;19(2):12.

18. Silver RT, Krichevsky S, Cross NCP Evaluation of serum erythropoietin values as defined by 2016 World Health Organization criteria for the diagnosis of polycythemia vera. Leuk Lymphoma. 2017;58(11):2768-2769.

19. Ancochea A, Alvarez-Larran A, MoralesIndiano $\mathrm{C}$, et al. The role of serum erythropoietin level and JAK2 v617f allele burden in the diagnosis of polycythemia vera. $\mathrm{Br} \mathrm{J}$ Haematol. 2014;167(3):411-417.

20. Rumi E, Pietra D, Ferretti V, et al. JAK2 or CALR mutation status defines subtypes of essential thrombocythemia with substantially different clinical course and outcomes. Blood. 2014;123(10):1544-1551.

21. "Laboratory Testing Information Erythropoietin." RSS 20 In Focus. ARUP
Laboratories, Web. 28 Feb. 2013 http://www.aruplab.com/guides/ug/tests/0 050227.jsp>.

22. Price GL, Davis KL, Karve S, Pohl G Walgren RA. Survival Patterns in United States (US) Medicare Enrollees with NonCML Myeloproliferative Neoplasms (MPN). PLoS One. 2014;9(3):e90299.

23. Michiels JJ, Medinger M, Raeve HD, et al Increased erythrocyte count on top of bone marrow histology but not serum EPO level or JAK2 mutation load discriminates between JAK2V617F mutated essential thrombocythemia and polycythemia vera. J Hematol Thromb Dis. 3:S1-001.

24. Pearson TC, Guthrie DL, Simpson J, et al Interpretation of measured red cell mass and plasma volume in adults: Expert Panel on Radionuclides of the International Council for Standardization in Haematology. Br J Hematol. 1995;89(4): 745-756. 